\title{
Environmental Nanoparticles Interactions with Plants: Morphological, Physiological, and Genotoxic Aspects
}

\author{
C. Remédios, F. Rosário, and V. Bastos \\ CESAM and Department of Biology, University of Aveiro, Campus Universitário de Santiago, 3810-193 Aveiro, Portugal \\ Correspondence should be addressed to C. Remédios, remedios@ua.pt
}

Received 15 February 2012; Revised 9 April 2012; Accepted 10 April 2012

Academic Editor: Helena Oliveira

Copyright () 2012 C. Remédios et al. This is an open access article distributed under the Creative Commons Attribution License, which permits unrestricted use, distribution, and reproduction in any medium, provided the original work is properly cited.

\begin{abstract}
Nanoparticles (NPs) are characterized by their small size (less than $100 \mathrm{~nm}$ ) and large surface area, which confer specific physicochemical properties as strength, electrical, and optical features. NPs can be derived from natural or anthropic sources, such as engineered or unwanted/incidental NPs. The composition, dimension, and morphology of engineered NPs enable their use in a variety of areas, such as electronic, biomedical, pharmaceutical, cosmetic, energy, environmental, catalysis, and materials science. As nanotechnology is an innovative and scientific growth area with an exponential production, more information is needed concerning the impacts of these nanomaterials (NMs) in the environment and, particularly, in animals/humans health and in plants performance. So, research on NPs as emerging contaminants is therefore a new field in environmental health. This minireview describes, briefly, the NPs characterization and their occurrence in the environment stating air, water, and soil. Finally, particular emphasis is given to the interaction of NPs with plants at different levels: morphology, physiology, and genotoxicity. By analyzing this compiled information, it is evident that research on NPs phytotoxicity is in the beginning, and more comprehensive studies are needed not only on NPs cytotoxicity and genotoxicity but also on the best and the most reliable methods of assessing NPs toxicity.
\end{abstract}

\section{Introduction}

1.1. Historical Overview. In 1959, Richard Freynman, an American physicist and Nobel laureate, firstly used the concept of nanotechnology, reporting the lecture "There's plenty room at the bottom" [1]. The Japanese researcher Professor Norio Taniguchi, in 1974, was the first to use the term nanotechnology, reporting "nanotechnology mainly consists of the processing of separation, consolidation, and deformation of materials by one atom or by one molecule." Later, in 1980, Dr. K. Eric Drexler explored the concept of this emerging field, in particular promoting technological significance of nanoscale phenomena and devices. More recently, in 2000, to coordinate federal nanotechnology research and development, the United States National Nanotechnology Initiative was founded (e.g., see http://www.nano.gov/).

Nowadays, nanotechnology is a revolutionary science, with predicted evolution within the next decades that may have equivalence with the ones observed for other industries, as the one of computers during the second half of the last century or earlier with the automobile industry (please see http://www.nanotechnologyresearchfoundation.org/nanohistory.html). This emerging nanoparticles (NPs) industry is expected to contribute to diverse products and services and to serve multiple consumers' purposes. However, and despite the success of nanotechnology, the release of NPs to the environment remains unknown, mostly due to the lack of scientific knowledge concerning the potential health and environmental risks associated with nanomaterials (NMs). In this minireview, we will describe the potential hazards of NPs in the environment and their interactions with plants. Despite this, NPs are being considered in the restrict group of emerging contaminants by, for example, some European countries (e.g., http://files.nanobio-raise.org/Downloads/ scenihr.pdf) and the United States Environmental Protection Agency (EPA) (e.g., http://www.epa.gov/fedfac/pdf/ emerging_contaminants_nanomaterials.pdf).

1.2. Nanoparticles Description. The unit nanometer was derived from the Greek "nano" which means "dwarf," since 
nanometers are referred to particles smaller than $1000 \mathrm{~nm}$ or $1 \mu \mathrm{m}$ [2]. However, NMs have been considered to be substances with a dimension less than $100 \mathrm{~nm} \mathrm{[2-10].}$

NPs, considering the building blocks of nanotechnology [6], have at least one dimension at $100 \mathrm{~nm}$ or less, which provides a high surface/volume ratio, leading to high reactivity (increasing the potential to cross cell membranes) [10] or intrinsic toxicity of the surface $[11,12]$. These factors act together and can change or enhance properties of NPs, such as strength, electrical properties, and optical characteristics [10]. Moreover, their small size and large surface area can determine the harmful potential of NPs [12].

\section{Nanoparticles Classification}

NPs can be classified regarding to their dimensionality, morphology, composition, uniformity, and agglomeration [2], since they can be spherical, tubular, irregularly shaped and can also exist in fused, aggregated or agglomerated forms [4]. Dimensionality refers to their shape or morphology, which can classify them on their number of dimensions, such as one-dimensional (1D), two-dimensional (2D), threedimensional (3D) NMs.

The characteristics to be taken relatively to NPs morphology are flatness, sphericity, and aspect ratio. NPs can be composed of single material or several materials; composites of various agglomerated materials can be found in nature, although single composites can be easily synthesized today. In respect to uniformity and agglomeration, NPs can exist as dispersed aerosols, suspensions/colloids, or in agglomerate state, due to their different chemistry and electromagnetic properties. Despite some diverse classifications of NPs that can be found, one can in general divide the following classes according to their composition (e.g., [13]):

(1) carbon-based materials (e.g., C60 fullerene), with particular potential in carbon nanotubes technology,

(2) metal-based substances (e.g., Ag, Au, and nanometal oxides), among the last ones, for example, those of titanium oxide are of particular interest,

(3) dendrimers, polymers consisting of branched units,

(4) bio-inorganic complexes (e.g., titanium with attached DNA strands) [13].

\section{Nanoparticles Sources}

NPs can be derived from natural and anthropogenic sources (engineered and unwanted or incidental NPs) [4, 14-16]. The natural processes that produce NPs can be photochemical reactions, volcanic eruptions, forest fires, simple erosion, and by plants and animals (shedding of skin and hair) [2]. Otherwise, anthropogenic sources refer to the following:

(1) engineered NMs classified as carbon NMs, metal oxide NPs, zero-valence metal NPs, quantum dots (QDs) and dendrimers [10],

(2) unwanted or incidental NPs from by-products of simple combustion, food cooking, and chemical manufacturing; welding or refining and smelting; combustion in vehicle and airplane engines; combustion of treated pulverized sewage sludge; and combustion of coal and fuel oil for power generation.

From their multiple conformation, composition, and nature, NPs present multiple functions and almost infinite applications. Nanotechnology has, therefore, gained a place as an emerging science with a recent rise in interest of NPs, mostly due to our increasing ability to synthesize and manipulate such particles.

Thus, nanoscale materials have a variety of uses in different areas, such as electronic, biomedical, pharmaceutical, cosmetic, energy, environmental, catalytic, and material applications [4], as described below.

\section{Nanoparticles Applications}

NMs have diverse applications, which can be summarized as follows [14, 17]: sunscreens and cosmetics (nanosized titanium dioxide and zinc oxide in sunscreens, nanosized iron oxide in some lipsticks); shampoos and detergents (nanosized alumina); window panes and ceramic tiles (nanostructured titanium oxides); pharmaceutical products; medical implants; food packaging; biosensors and agents for environmental remediation; water treatment technology; composites (mechanical, optical, electrical, and magnetic properties); clays (construction materials); coatings and surfaces; tougher and harder cutting tools; paints; displays (television screens and computer monitors); batteries (growth in portable electronic equipment); fuel additives; carbon nanotube composites; lubricants (nanosized "ball bearings"); magnetic materials; machinable ceramics; and military battle suits.

However, and considering the statement that all technology comes with a price, nanotechnology could lead to environmental hazards and adverse health effects [1].

\section{Nanotoxicology}

Primary geogenic NPs may form as aerosols from, for example, sprays of salts and sulfates mostly from the sea, or as sulfate aerosols from volcanic emissions, or even as forest fires (soot and/or polycyclic aromatic hydrocarbons) [18].

Moreover, NPs may be introduced in the environment by anthropic reasons, being introduced, for example, intentionally to remediate groundwater and contaminated soil $[19,20]$, or also unintentionally by several sources, as research and clinical settings and solid or liquid waste streams production facilities [21]. The biggest risk of release of this material may occur during transportation to good manufacturers and by intentional releases for environmental application [20, 21].

The toxicity and degradation of these compounds in the environment cannot be accurately assessed yet because it depends on the NPs type, physicochemical properties, and also the environment media in which they partition and the respective conditions. So, this is a field that requires intense research. For example, it is recognized that research needs to 
be performed in the following fields: (a) detection of NPs in the environment, (b) measurement of emissions of NPs, (c) life-cycle of NPs in the environment, (d) toxicity of NPs to the environment, and (e) immediate and longer impact on environment (e.g., http://www.nanocap.eu/).

The concern of NPs exposure is due to some important issues, as these materials half-lives that may be months to possibly years, the increase on concentration of anthropic substances since NPs are often produced in a large scale, and because this material is expected to be accumulated and transformed by time and local environmental conditions $[20,22]$.

The current knowledge about NPs and the challenges of nanotoxicity assessment lead to a lack of effective regulation of NPs use. Some governmental entities, as EPA, have been conducting efforts in order to not only comprehend the properties of NPs and their potential risks for human health and the environment but also to regulate the use, storage, and disposal of these materials to allow a safe and sustainable nanotechnology development. Although there are no specific environmental laws, NPs cut across some existing EPA regulations. For example, several NMs are considered chemical substances under the Toxic Substances Control Act, and pesticides containing nanotechnology products are regulated under the Federal Insecticide, Fungicide, and Rodenticide Act (see http://www.epa.gov/nanoscience/). Still, a recent report from EPA's Office of Inspector General stated that “... EPA does not currently have sufficient information or processes to effectively manage the human health and environmental risks of nanomaterials..." and that "... EPA has the statutory authority to regulate nanomaterials but currently lacks the environmental and human health exposure and toxicological data to do so effectively" [23]. According to this report, some proposed policies have failed, and others that await approval are facing significant barriers to their effectiveness [23].

\section{Transport and Interactions}

Transport of NPs through environment partition is the most critical parameter to evaluate NPs impact, expecting high mobility of NPs that are designed to be released into the environment [24]. Transport and, therefore, NPs mobility are determined by forces, such as London-van der Waals and double-layer forces that are responsible for attachment. This phenomenon is called Brownian motion (diffusion). Gravity and fluid motion are also factors that influence transport of NPs $[7,8,14]$.

NPs are predicted to have high efficiency of transport to collector surfaces due to Brownian diffusion, and their potential mobility may be predicted by knowing the exact surface properties of NPs. The surface properties of engineered NPs are of essential importance for their aggregation behavior, and thus for their mobility in aquatic and terrestrial systems and interactions with algae, plants, and fungi $[19,25$, 26].

NPs can interact with toxic compounds, and it can both amplify the toxic effect and have a positive role in the environment, alleviating the toxicity of the compounds. There are two scenarios of possible NP-pollutant-cell interactions: NPs may adsorb (absorb) the pollutant and decrease the free concentration, resulting in a reduction of pollutant uptake by organisms, and there is also the possibility of NPpollutant uptake (adsorbed) by the organisms, in which the toxic effect could be caused either by NPs pollutant or the synergistic way by both together [4].

One of the positive applications of NPs in the environment is precisely its use in bioremediation and as anticontaminants in the removal of pollutants from soil and water systems. Their unique surface properties and size have an advantageous role in the direct conversion of the contaminant, in the pollutant-NP surface reaction, and in the aggregation/incorporation of the pollutant into colloids (contaminants are transported with colloids and removed) $[4,19,27]$. Engineered NPs can be synthesized with controlled properties to enhance their selectivity for the pollutant and reactions steps. This can lower the costs of removing pollutants from the environment and can also reduce the concentration of NPs needed for this purpose [14, $27,28]$. For instance, nanoscale zero-valent iron (nZVImade by reduction of solutions of metal salts) is widely used for groundwater, sediments, and soils remediation. Quinn and collaborators [29] and Elliott and Zhang [30] injected nZVI into the groundwater and obtained successful results in remediation. nZVI removes nitrates by reduction and, being a metallic iron, is effective in degrading a wide variety of common contaminants (chlorinated ethenes, chlorinated methanes, brominated methanes, pesticides, and dyes) [4, 27]. Nevertheless, more in vitro tests should be carried out before in situ large-scale tests are performed. Despite the control of the production of enhanced NPs (controlled size, composition, and morphology) more precaution is needed, because this nanoscale material is too reactive and their benefic role may turn into a negative one when released into the environment.

\section{Fate and Behavior of Nanoparticles in the Environment}

7.1. Air. There is a natural background of NPs (ultrafine particles-smaller than $0.1 \mu \mathrm{m}$ ) in the atmosphere and, despite little work has been done on ecological system, it is known that, when compared to anthropogenic sources and potential released manufactured NPs, the natural background present in the air is considerably low $[19,31]$.

NPs have short residence time. However they attach to accumulation mode particles and remain in the atmosphere as long as the accumulation mode particles participate in the atmospheric chemistry and physics. Diesel NPs are one of the concerning NPs released into the atmosphere. These NPs contribute to global warming since they absorb light and also endanger human health.

When ultrafine particles are directly released from the source, they are called primary particles; volatile NPs (secondary NPs) composed by nucleation mode may be formed in the atmosphere by photochemical processes. 
The key species in the atmosphere are sulfuric acid, nitric acid, and organic gases $[4,14]$. Some conditions (e.g., temperature, residence time, dilution rate, dilution ratio, and concentration of carbon particles) are necessary for production of these secondary NPs [32-35].

Therefore, this event will result in an increasing of particle number concentration above their natural concentration present in the atmosphere; besides, these nucleation particles may continue to grow by vapor condensation and coagulation, which result in atmospheric optical effects, building soiling, and climate change $[4,14,36,37]$.

7.2. Water. Industrial products and wastes tend to end up in waterways, increasing the possibility of NPs contamination, although almost no current data on behavior and fate of NPs in aquatic systems is available [4].

Colloids, particles in the $1 \mathrm{~nm}$ to $1 \mu \mathrm{m}$ size range, are macromolecules and molecular assemblies. They include organic (e.g., primarily humic substances (HS) and fibrillar material, usually protein and polysaccharide exudates from microbes) and inorganic matter (e.g., $\mathrm{Fe}, \mathrm{Mn}, \mathrm{Al}$, and $\mathrm{Si}$ oxides, and thus analogous to manufactured metal oxide NPs), and also biological material (e.g., bacteria) [4, 19]. Colloidal fate and behavior are determined by aggregation. Colloids tend to aggregate to particles $(>1 \mu \mathrm{m})$, and their transport depends on the first one, being denominated sedimentation. Like metals, manufactured NPs tend to aggregate and subsequently settle. This process has positive effects on water bodies' purification, because this behavior results in a transfer of NPs from water column to sediments, resulting in a pollutant loss.

Despite this possible pollutant loss, natural colloids interact with NPs and this will affect the NPs behavior, being more difficult to predict the NPs effect on the aquatic system. Knowing NPs size, surface charges, and chemical reactivity, it is possible to predict some potential biological effects in the aqueous environment, such as generation of ROS, phototoxicity and photocatalytic activity, and interaction with soluble pollutants [25], but due to the aquatic system complexity this physical behavior is hard to predict.

Oceans exhibit changes in physicochemical characteristics with depth (e.g., temperature) that may influence aggregation and colloid chemistry. Analogously to freshwater aggregates of NPs may sink into the ocean floor, as well as accumulate at the interface between cold and warm currents or be recycled by biota. This may threaten pelagic species since they feed at these zones, while deposition in the sediment may present a risk of exposure to benthic species. NPs may also accumulate on the surface microlayers of the oceans, presenting a route of aerosol exposure risk to marine birds and mammals, as well as the organisms living on the surface microlayer $[38,39]$. Oberdörster et al. [40] exposed freshwater crustaceans Daphnia magna, the marine copepod Hyalella azteca, and fish, such as Pimephales promelas and Oryzias latipes, to C60 (fullerenes), and toxicity was reported. Kashiwada [41] reported an increase in toxicity with the salinity enhancement, along with a greater tendency for the particles to form aggregates, when eggs of Japanese medaka were exposed to fluorescent NPs $(30 \mathrm{mg} / \mathrm{L})$ at different salinities. At salinities similar to the ones found in normal seawater, accumulation decreased, but egg mortality remained high.

Therefore, it is not possible to predict or evaluate the impact of NPs on aquatic systems; however, ecotoxicological studies show that aquatic organisms, both unicellular and animals, are affected by NPs toxicity $[4,42,43]$.

7.3. Soil. Soil and sediments are the ultimate sinks of NPs and, whether directly or indirectly released (e.g., via sewage treatment plants, aerial deposition, or waste handling), NPs will end up in soil; this system may present the most significant exposure avenue for assessing environmental risk. Being soil one of the main sinks, it raises concern about the entry of NPs into food webs and human access to contaminated agriculture [44].

In terrestrial ecosystems, natural NPs are present (soil colloids), such as organic matter, clays, iron oxides, and other minerals that play an important role in biogeochemical processes. Therefore, the introduction of manufactured NPs in this ecosystem may change the profile of the natural NPs and interfere with soil development (pedogenesis) or behavior (e.g., crusting and dispersion) [19, 45].

The fate of NPs in terrestrial ecosystems is difficult to elucidate, and there is few data that report transport of NPs through soils. NPs are made to have different properties than their similar bulk and macroscopic material, and these differences may change fate and effects of NPs in terrestrial environment $[19,46,47]$. The high surface area, reactivity, size, aggregation, and absorbance are important determinants of their adhesion to soil, and thus their mobility and transport [48].

Bioavailability of NPs also depends on specific properties of each NP, in addition to composition of the soil matrix, porosity, hydraulic conductivity, groundwater gradient and flow velocity, and geochemical properties (e.g., dissolved oxygen, $\mathrm{pH}$, ionic strength, and concentrations of nitrate, nitrite, and sulfate) $[4,19,43]$. Unrine et al. [44] reported absorption, biodistribution through tissues and statistically significant decrease in reproduction of earthworms Eisenia fetida when exposed to Au NPs. This study demonstrates the importance of considering food chain accumulation and trophic transfer, but information that NPs end up in higher-level organisms is extremely limited [49].

NPs have been extensively used as antimicrobial agents against pathogenic bacteria, but this abusive use is leading to negative consequences against the populations of soil microbes that play beneficial roles in the environment, such as promoting plant growth, element cycling, and degradation of pollutants. The NPs of $\mathrm{Ag}, \mathrm{CuO}$, and $\mathrm{ZnO}$ showed both toxicity on pathogenic bacteria (e.g., Escherichia coli and Staphylococcus aureus) and beneficial effects on microbes, as Pseudomonas putida, which has bioremediation potential and is a strong root colonizer [50,51]. These NPs showed higher toxicity when compared to their equivalent bulk materials $[22,52]$. 
Therefore, being terrestrial systems the larger and most reactive sink for NPs, more research and standardized testing protocols are needed for fate/behavior and food web accumulation of NPs.

\section{Interaction of Nanoparticles with Plants}

As pointed before, the increasing applications and use of NPs are directly related to their release in the environment. The effects of NPs have been described in a wide variety of organisms, such as microorganisms [53, 54], protozoa [55], invertebrates [56, 57], and vertebrates [58].

However, interactions of NPs with plants and other organisms that share similarities with plant cells, such as algae, have been poorly studied, remaining unclear the general consequences of NPs exposure for plant cells [59]. The lack of these data leads as well to a defective understanding of how NMs are transferred and accumulate in the various food chain levels [60]. We will describe below some of the most relevant studies on NPs toxicity in plants.

\subsection{NPs Phytotoxicity: Morphological and Physiological Data.} The effects of $\mathrm{Fe}_{3} \mathrm{O}_{4}, \mathrm{TiO}_{2}$, and carbon NPs were assessed on cucumber plants [61]. These NPs were found to negatively affect seed germination rate, root elongation, and germination index. Also, five NPs (multiwalled carbon nanotubes (MWCNTs), $\mathrm{Ag}, \mathrm{Cu}, \mathrm{ZnO}$, and $\mathrm{Si}$ ) were tested on Cucurbita pepo in suspensions up to $1000 \mathrm{mg} / \mathrm{L}$ [62] The authors found different effects from the NPs and their counterparts, concerning seed germination, root elongation and biomass [62]. No exposure reduced germination rates, but $\mathrm{Cu}$ NPs reduced emerging root length. Also, exposure to Ag NPs decreased plant biomass and transpiration. These authors concluded that they demonstrated "... that standard phytotoxicity tests such as germination and root elongation may not be sensitive enough or appropriate when evaluating nanoparticle toxicity to terrestrial plant species" [62].

In another study, Zhang and collaborators [59] compared the phytotoxicity of nanoparticulate $\mathrm{Yb}_{2} \mathrm{O}_{3}$, bulk $\mathrm{Yb}_{2} \mathrm{O}_{3}$, and $\mathrm{YbCl}_{3} \cdot 6 \mathrm{H}_{2} \mathrm{O}$ to cucumber plants. They studied the toxicity, distribution, and biotransformation of the three materials in plant roots and found that with the nano- $\mathrm{Yb}_{2} \mathrm{O}_{3}$ exposure, $\mathrm{YbPO}_{4}$ deposits were found in the cytoplasm of root cells. The putative toxicity of these compounds was then discussed by the authors [59].

Other study on root cells of Allium cepa reported that $\mathrm{ZnO}$ NPs exert cytotoxic and genotoxic effects, including lipid peroxidation, decreasing of the mitotic index, and increasing of the micronuclei and chromosomal aberration indexes [63]. Ma and colleagues [64] evaluated the effects of four rare earth oxide NPs (nano- $\mathrm{CeO}_{2}$, nano- $\mathrm{La}_{2} \mathrm{O}_{3}$, nano- $\mathrm{Gd}_{2} \mathrm{O}_{3}$, and nano- $\mathrm{Yb}_{2} \mathrm{O}_{3}$ ) on root elongation of seven higher plant species. Different NPs caused distinct effects on root growth, and these effects also varied between plant species, being lettuce the most sensitive one. The surface modification of NPs has been shown to alter the phytotoxicity induced by these materials. A recent study reporting the interaction of $\mathrm{SiO}_{2} \mathrm{NPs}$ with algae showed that alumina coated $\mathrm{SiO}_{2} \mathrm{NPs}$ were less toxic to Pseudokirchneriella subcapitata than bare $\mathrm{SiO}_{2} \mathrm{NPs}$ [65].

On the other hand, several studies demonstrated that NPs can also have no significant or positive effects on plants. $\mathrm{Al}_{2} \mathrm{O}_{3}$ NPs at concentrations up to $4000 \mathrm{mg} / \mathrm{L}$ had no significant toxic effects on seed germination, root elongation, and number of leaves of Arabidopsis thaliana [66]. One study showed that $10-40 \mathrm{mg} / \mathrm{L}$ of carbon nanotubes increased seed germination and growth of tomato plants [67]. The authors suggest that these effects are due to carbon nanotubes ability to penetrate the seed coat and enhance the crucial water uptake, although these specific mechanisms were not reported. Nano- $\mathrm{TiO}_{2}$ was also found to improve energy utilization and conversion efficiency in D1/D2/Cyt b559 complex of spinach [68], which could explain the enhancement of spinach growth by $\mathrm{TiO}_{2}$ reported in other articles.

Larue and collaborators [69] studied the effects of $\mathrm{TiO}_{2}-$ NPs on Triticum aestivum, Brassica napus, and Arabidopsis thaliana. They showed that these NPs were absorbed by plants and did not affect their germination and root elongation. The authors also highlighted the need of more studies of NPs toxicity, and in particular on NPs interaction with plants.

Despite the studies reported above, Rico and collaborators [70] recognized that "most of the studies reported the effect of nanomaterials on seed germination or 15-dayold seedlings, and few describe the biotransformation of nanomaterials in food crops, and the possible transmission of the nanomaterials to the next generation of plants exposed to nanomaterials is unknown." So, it is urgent not only to further elucidate the effects of NPs in plants in order to characterize the uptake, phytotoxicity, and accumulation of NPs, but also to understand how nanoscale materials can affect food chains and, ultimately, to human health risk assessment.

Moreover a main question remains, that is, which are the best standard phytotoxicity tests that may be used in assessing NPs toxicity? For example, most of the studies up to moment were based on germination and root elongation, which are not sensitive enough or appropriate when evaluating NP toxicity to terrestrial plant species [71].

8.2. NPs and Genotoxicity in Plants. Few is known on the NPs induced genotoxicity in plants and most of the few available information dates from the two last years. Atha and collaborators [72] reported for the first time that copper oxide NPs damaged DNA in some agricultural and grassland plants (Raphanus sativus, Lolium perenne, and Lolium rigidum). It seems that oxidatively modified compounds accumulated and led to mutagenic DNA lesions, which inhibited plant growth. This isolated study on NPs genotoxicity in plants strongly supports the urgent need to evaluate the putative genotoxicity of the different NPs classes in plants and at which concentrations. Another issue that deserves attention is the analysis of genotoxic endpoints for NPs genotoxicity. For example, Comets, FCM-HPCV, and micronuclei have provided similar information in metal 
genotoxicity in plants (e.g., [71]), but any generalization to NPs-induced phytogenotoxicity should be done carefully.

\section{Conclusion}

NPs technology is an emerging field with multiple potentialities and applications. However, and due to the particular characteristics that NPs have when compared to their individual components, NPs may present also different toxicity profiles. Despite NPs have always been present in the environment, the concern on their toxicity has only emerged during the last decade, with the increase of NPs industry and multiple applications. Few studies are available and most are focused on microorganisms and animals/human cells. On the other hand, putative toxicity in plants is by far less studied. It is so important to understand that not all NPs are toxic. From the few available data, some remain controversial, as some NPs seem to be nontoxic and others appear to have beneficial health effects. On the contrary, others seem to be cytotoxic for different organisms, and even genotoxicity was already described for plants.

So, several countries recognized the need to study NPs toxicity and considered them as emerging contaminants. More information is needed regarding the potential impacts that NPs release may have on environmental and animals health.

The uptake, bioaccumulation, biotransformation, and risks of NMs for food crops are still not well understood. Very few NMs and plant species have been studied, mainly at the very early growth stages of the plants. Most of the studies, except one with MWCNTs performed on the model plant Arabidopsis thaliana and another with ZnO NPs on Ryegrass, reported the effect of NMs on seed germination or 15-day-old seedlings. Very few references describe the biotransformation of NMs in food crops, and the possible transmission of the NMs to the next generation of plants exposed to NMs is unknown. The possible biomagnification of NPs in the food chain is also unknown.

\section{References}

[1] A. D. Maynard, R. J. Aitken, T. Butz et al., "Safe handling of nanotechnology," Nature, vol. 444, no. 7117, pp. 267-269, 2006.

[2] C. Buzea, I. I. Pacheco, and K. Robbie, "Nanomaterials and nanoparticles: sources and toxicity," Biointerphases, vol. 2, no. 4, pp. MR17-MR71, 2007.

[3] N. J. Walker and J. R. Bucher, "A 21st century paradigm for evaluating the health hazards of nanoscale materials?" Toxicological Sciences, vol. 110, no. 2, pp. 251-254, 2009.

[4] B. Nowack and T. D. Bucheli, "Occurrence, behavior and effects of nanoparticles in the environment," Environmental Pollution, vol. 150, no. 1, pp. 5-22, 2007.

[5] G. Oberdorster, A. Maynard, K. Donaldson et al., "Principles for characterizing the potential human health effects from exposure to nanomaterials: elements of a screening strategy," Particle and Fibre Toxicology, vol. 2, no. 8, 2005.

[6] S. T. Stern and S. E. McNeil, "Nanotechnology safety concerns revisited," Toxicological Sciences, vol. 101, no. 1, pp. 4-21, 2008.
[7] R. D. Handy, R. Owen, and E. Valsami-Jones, "The ecotoxicology of nanoparticles and nanomaterials: current status, knowledge gaps, challenges, and future needs," Ecotoxicology, vol. 17, no. 5, pp. 315-325, 2008.

[8] R. D. Handy, F. von der Kammer, J. R. Lead, M. Hassellöv, R. Owen, and M. Crane, "The ecotoxicology and chemistry of manufactured nanoparticles," Ecotoxicology, vol. 17, no. 4, pp. 287-314, 2008.

[9] R. J. Aitken, M. Q. Chaudhry, A. B. A. Boxall, and M. Hull, "Manufacture and use of nanomaterials: current status in the UK and global trends," Occupational Medicine, vol. 56, no. 5, pp. 300-306, 2006.

[10] M. Farre, J. Sanchis, and D. Barcelo, "Analysis and assessment of the occurrence, the fate and the behavior of nanomaterials in the environment," Trends in Analytical Chemistry, vol. 30, no. 3, pp. 517-527, 2011.

[11] I. Das and S. A. Ansari, "Nanomaterials in science and technology," Journal of Scientific and Industrial Research, vol. 68, no. 8, pp. 657-667, 2009.

[12] K. Donaldson, V. Stone, C. L. Tran, W. Kreyling, and P. J. A. Borm, "Nanotoxicology," Occupational and Environmental Medicine, vol. 61, no. 9, pp. 727-728, 2004.

[13] U.S. EPA. Science Policy Council, "Nanotechnology white paper," Tech. Rep. EPA 100/B-07/001, U.S. Environmental Protection Agency, Washington, DC, USA, 2007.

[14] P. Biswas and C. Y. Wu, "2005 critical review: nanoparticles and the environment," Journal of the Air \& Waste Management Association, vol. 55, no. 6, pp. 708-746, 2005.

[15] G. Lidén, "The European commission tries to define nanomaterials," Annals of Occupational Hygiene, vol. 55, no. 1, pp. 1-5, 2011.

[16] T. Tervonen, I. Linkov, J. R. Figueira, J. Steevens, M. Chappell, and M. Merad, "Risk-based classification system of nanomaterials," Journal of Nanoparticle Research, vol. 11, no. 4, pp. 757766, 2009.

[17] The Royal Society \& The Royal Academy of Engineering, Nanoscience and Nanotechnologies: Opportunities and Uncertainties, The Royal Society \& The Royal Academy of Engineering, London, UK, 2004.

[18] W. E. Motzer, "Nanomaterials: new emerging contaminants and their potential impact to water resources," http://www .grac.org/Nanomaterials_and_Water_Resources.pdf.

[19] S. J. Klaine, P. J. J. Alvarez, G. E. Batley et al., "Nanomaterials in the environment: behavior, fate, bioavailability, and effects," Environmental Toxicology and Chemistry, vol. 27, no. 9, pp. 1825-1851, 2008.

[20] E. Flahaut, "Introduction to the special focus issue: environmental toxicity of nanoparticles," Nanomedicine, vol. 5, no. 6 , pp. 949-950, 2010.

[21] P. C. Ray, H. Yu, and P. P. Fu, "Toxicity and environmental risks of nanomaterials: challenges and future needs," Journal of Environmental Science and Health C, vol. 27, no. 1, pp. 1-35, 2009.

[22] R. Hardman, "A toxicologic review of quantum dots: toxicity depends on physicochemical and environmental factors," Environmental Health Perspectives, vol. 114, no. 2, pp. 165-172, 2006.

[23] U.S. EPA. Office of Inspector General, "EPA needs to manage nanomaterial risks more effectively," Tech. Rep. 12-P-0162, U.S. Environmental Protection Agency, Washington, DC, USA, 2011.

[24] W. X. Zhang and C. B. Wang, "Synthesizing nanoscale iron particles for rapid and complete dechlorination of TCE and 
PCBs," Environmental Science and Technology, vol. 31, no. 7, pp. 2154-2156, 1997.

[25] M. Auffan, J. Y. Bottero, C. Chaneac, and J. Rose, "Inorganic manufactured nanoparticles: how their physicochemical properties influence their biological effects in aqueous environments," Nanomedicine, vol. 5, no. 6, pp. 999-1007, 2010.

[26] E. Navarro, A. Baun, R. Behra et al., "Environmental behavior and ecotoxicity of engineered nanoparticles to algae, plants, and fungi," Ecotoxicology, vol. 17, no. 5, pp. 372-386, 2008.

[27] W.-X. Zhang, "Nanoscale iron particles for environmental remediation: an overview," Journal of Nanoparticle Research, vol. 5, no. 3-4, pp. 323-332, 2003.

[28] J. F. Banfield and H. Zhang, "Nanoparticles in the environment," Reviews in Mineralogy and Geochemistry, vol. 44, pp. $1-58,2001$.

[29] J. Quinn, C. Geiger, C. Clausen et al., "Field demonstration of DNAPL dehalogenation using emulsified zero-valent iron," Environmental Science and Technology, vol. 39, no. 5, pp. 13091318, 2005.

[30] D. W. Elliott and W. X. Zhang, "Field assessment of nanoscale bimetallic particles for groundwater treatment," Environmental Science and Technology, vol. 35, no. 24, pp. 4922-4926, 2001.

[31] G. Oberdörster, E. Oberdörster, and J. Oberdörster, "Concepts of nanoparticle dose metric and response metric [1]," Environmental Health Perspectives, vol. 115, no. 6, p. A290, 2007.

[32] I. Abdul-Khalek, D. Kittelson, and F. Brear, "The influence of dilution conditions on diesel exhaust particle size distribution measurements," SAE Technical Paper 1999-01-1142, 1999.

[33] I. Abdul-Khalek, D. B. Kittelson, B. R. Graskow, Q. Wei, and F. Bear, "Diesel exhaust particle size: measurement issues and trends," SAE Technical Paper 980525, 1998.

[34] U. Mathis, J. Ristimäki, M. Mohr et al., "Sampling conditions for the measurement of nucleation mode particles in the exhaust of a diesel vehicle," Aerosol Science and Technology, vol. 38, no. 12, pp. 1149-1160, 2004.

[35] L. Morawska, Z. Ristovski, E. R. Jayaratne, D. U. Keogh, and $\mathrm{X}$. Ling, "Ambient nano and ultrafine particles from motor vehicle emissions: characteristics, ambient processing and implications on human exposure," Atmospheric Environment, vol. 42, no. 35, pp. 8113-8138, 2008.

[36] P. H. Mcmurry, K. S. Woo, R. Weber, D. R. Chen, and D. Y. H. Pui, "Size distributions of 3-10 nm atmospheric particles: implications for nucleation mechanisms," Philosophical Transactions of the Royal Society A, vol. 358, no. 1775, pp. 26252642, 2000.

[37] J. P. Shi, D. E. Evans, A. A. Khan, and R. M. Harrison, "Sources and concentration of nanoparticles $(<10 \mathrm{~nm}$ diameter $)$ in the urban atmosphere," Atmospheric Environment, vol. 35, no. 7, pp. 1193-1202, 2001.

[38] C. B. Kennedy, S. D. Scott, and F. G. Ferris, "Hydrothermal phase stabilization of 2-line ferrihydrite by bacteria," Chemical Geology, vol. 212, no. 3-4, pp. 269-277, 2004.

[39] K. Simkiss, "Surface effects in ecotoxicology," Functional Ecology, vol. 4, no. 3, pp. 303-308, 1990.

[40] E. Oberdörster, S. Zhu, T. M. Blickley, P. McClellan-Green, and M. L. Haasch, "Ecotoxicology of carbon-based engineered nanoparticles: effects of fullerene (C60) on aquatic organisms," Carbon, vol. 44, no. 6, pp. 1112-1120, 2006.

[41] S. Kashiwada, "Distribution of nanoparticles in the seethrough medaka (Oryzias latipes)," Environmental Health Perspectives, vol. 114, no. 11, pp. 1697-1702, 2006.

[42] C. J. Smith, B. J. Shaw, and R. D. Handy, "Toxicity of single walled carbon nanotubes to rainbow trout, (Oncorhynchus mykiss): respiratory toxicity, organ pathologies, and other physiological effects," Aquatic Toxicology, vol. 82, no. 2, pp. 94109, 2007.

[43] Y. Zhu, Q. Zhao, Y. Li, X. Cai, and W. Li, “The interaction and toxicity of multi-walled carbon nanotubes with stylonychia mytilus," Journal of Nanoscience and Nanotechnology, vol. 6, no. 5, pp. 1357-1364, 2006.

[44] J. M. Unrine, S. E. Hunyadi, O. V. Tsyusko, W. Rao, W. A. Shoults, and P. M. Bertsch, "Evidence for bioavailability of $\mathrm{Au}$ nanoparticles from soil and biodistribution within earthworms (Eisenia fetida)," Environmental Science and Technology, vol. 44, no. 21, pp. 8308-8313, 2010.

[45] F. K. Cameron, "Soil colloids and the soil solution," Journal of Physical Chemistry, vol. 19, no. 1, pp. 1-13, 1915.

[46] R. F. Korcak and D. S. Fanning, "Availability of applied heavy metals as a function of type of soil material and metal source," Soil Science, vol. 140, no. 1, pp. 23-34, 1985.

[47] E. Smolders and F. Degryse, "Fate and effect of zinc from tire debris in soil," Environmental Science and Technology, vol. 36, no. 17, pp. 3706-3710, 2002.

[48] P. Borm, F. C. Klaessig, T. D. Landry et al., "Research strategies for safety evaluation of nanomaterials, Part V: role of dissolution in biological fate and effects of nanoscale particles," Toxicological Sciences, vol. 90, no. 1, pp. 23-32, 2006.

[49] H. Zhu, J. Han, J. Q. Xiao, and Y. Jin, "Uptake, translocation, and accumulation of manufactured iron oxide nanoparticles by pumpkin plants," Journal of Environmental Monitoring, vol. 10, no. 6, pp. 713-717, 2008.

[50] M. A. Molina, J. L. Ramos, and M. Espinosa-Urgel, "A two-partner secretion system is involved in seed and root colonization and iron uptake by Pseudomonas putida KT2440," Environmental Microbiology, vol. 8, no. 4, pp. 639-647, 2006.

[51] M. I. Ramos-González, M. J. Campos, and J. L. Ramos, "Analysis of Pseudomonas putida KT2440 gene expression in the maize rhizosphere: in vitro expression technology capture and identification of root-activated promoters," Journal of Bacteriology, vol. 187, no. 12, pp. 4033-4041, 2005.

[52] P. Gajjar, B. Pettee, D. W. Britt, W. Huang, W. P. Johnson, and A. J. Anderson, "Antimicrobial activities of commercial nanoparticles against an environmental soil microbe, Pseudomonas putida KT2440," Journal of Biological Engineering, vol. 3, p. 9, 2009.

[53] D. A. Pelletier, A. K. Suresh, G. A. Holton et al., "Effects of engineered cerium oxide nanoparticles on bacterial growth and viability," Applied and Environmental Microbiology, vol. 76, no. 24, pp. 7981-7989, 2010.

[54] C. O. Dimkpa, A. Calder, D. W. Britt, J. E. McLean, and A. J. Anderson, "Responses of a soil bacterium, Pseudomonas chlororaphis O6 to commercial metal oxide nanoparticles compared with responses to metal ions," Environmental Pollution, vol. 159, no. 7, pp. 1749-1756, 2011.

[55] M. Mortimer, K. Kasemets, and A. Kahru, "Toxicity of $\mathrm{ZnO}$ and $\mathrm{CuO}$ nanoparticles to ciliated protozoa Tetrahymena thermophila," Toxicology, vol. 269, no. 2-3, pp. 182-189, 2010.

[56] C. M. Zhao and W. X. Wang, "Comparison of acute and chronic toxicity of silver nanoparticles and silver nitrate to Daphnia magna," Environmental Toxicology and Chemistry, vol. 30, no. 4, pp. 885-892, 2011.

[57] J. Valant, D. Drobne, and S. Novak, "Effect of ingested titanium dioxide nanoparticles on the digestive gland cell membrane of terrestrial isopods," Chemosphere, vol. 87, no. 1, pp. 19-25, 2012.

[58] G. Federici, B. J. Shaw, and R. D. Handy, "Toxicity of titanium dioxide nanoparticles to rainbow trout (Oncorhynchus 
mykiss): gill injury, oxidative stress, and other physiological effects," Aquatic Toxicology, vol. 84, no. 4, pp. 415-430, 2007.

[59] P. Zhang, Y. Ma, Z. Zhang et al., "Comparative toxicity of nanoparticulate/bulk $\mathrm{Yb}_{2} \mathrm{O}_{3}$ and $\mathrm{YbCl}_{3}$ to cucumber (Cucumis sativus)," Environmental Science and Technology, vol. 46, no. 3, pp. 1834-1841, 2012.

[60] A. Kahru and H. C. Dubourguier, "From ecotoxicology to nanoecotoxicology," Toxicology, vol. 269, no. 2-3, pp. 105-119, 2010.

[61] Y. K. Mushtaq, "Effect of nanoscale $\mathrm{Fe}_{3} \mathrm{O}_{4}, \mathrm{TiO}_{2}$ and carbon particles on cucumber seed germination," Journal of Environmental Science and Health A, vol. 46, no. 14, pp. 1732-1735, 2011.

[62] D. Stampoulis, S. K. Sinha, and J. C. White, "Assay-dependent phytotoxicity of nanoparticles to plants," Environmental Science and Technology, vol. 43, no. 24, pp. 9473-9479, 2009.

[63] M. Kumari, S. S. Khan, S. Pakrashi, A. Mukherjee, and N. Chandrasekaran, "Cytogenetic and genotoxic effects of zinc oxide nanoparticles on root cells of Allium cepa," Journal of Hazardous Materials, vol. 190, no. 1-3, pp. 613-621, 2011.

[64] Y. H. Ma, L. L. Kuang, X. He et al., "Effects of rare earth oxide nanoparticles on root elongation of plants," Chemosphere, vol. 78, no. 3, pp. 273-279, 2010.

[65] K. Van Hoecke, K. A. C. De Schamphelaere, S. RamirezGarcia, P. Van der Meeren, G. Smagghe, and C. R. Janssen, "Influence of alumina coating on characteristics and effects of $\mathrm{SiO} 2$ nanoparticles in algal growth inhibition assays at various $\mathrm{pH}$ and organic matter contents," Environment International, vol. 37, no. 6, pp. 1118-1125, 2011.

[66] C. W. Lee, S. Mahendra, K. Zodrow et al., "Developmental phytotoxicity of metal oxide nanoparticles to Arabidopsis thaliana," Environmental Toxicology and Chemistry, vol. 29, no. 3, pp. 669-675, 2010.

[67] M. Khodakovskaya, E. Dervishi, M. Mahmood et al., "Carbon nanotubes are able to penetrate plant seed coat and dramatically affect seed germination and plant growth," ACS Nano, vol. 3, no. 10, pp. 3221-3227, 2009.

[68] M. Su, H. Liu, C. Liu, C. Qu, L. Zheng, and F. Hong, "Promotion of nano-anatase $\mathrm{TiO} 2$ on the spectral responses and photochemical activities of D1/D2/Cyt b559 complex of spinach," Spectrochimica Acta A, vol. 72, no. 5, pp. 1112-1116, 2009.

[69] C. Larue, H. Khodja, N. Herlin-Boime et al., "Investigation of titanium dioxide nanoparticles toxicity and uptake by plants," Journal of Physics, vol. 304, no. 1, Article ID 012057, 2011.

[70] C. M. Rico, S. Majumdar, M. Duarte-Gardea, J. R. PeraltaVidea, and J. L. Gardea-Torresdey, "Interaction of nanoparticles with edible plants and their possible implications in the food chain," Journal of Agricultural and Food Chemistry, vol. 59, no. 8, pp. 3485-3498, 2011.

[71] E. Rodriguez, R. Azevedo, P. Fernandes, and C. Santos, "Cr(VI) induces DNA damage, cell cycle arrest and polyploidization: a flow cytometric and comet assay study in Pisum sativum," Chemical Research in Toxicology, vol. 24, no. 7, pp. 1040-1047, 2011.

[72] D. H. Atha, H. Wang, E. J. Petersen et al., "Copper oxide nanoparticle mediated DNA damage in terrestrial plant models," Environmental Science and Technology, vol. 46, no. 3, pp. 1819-1827, 2012. 

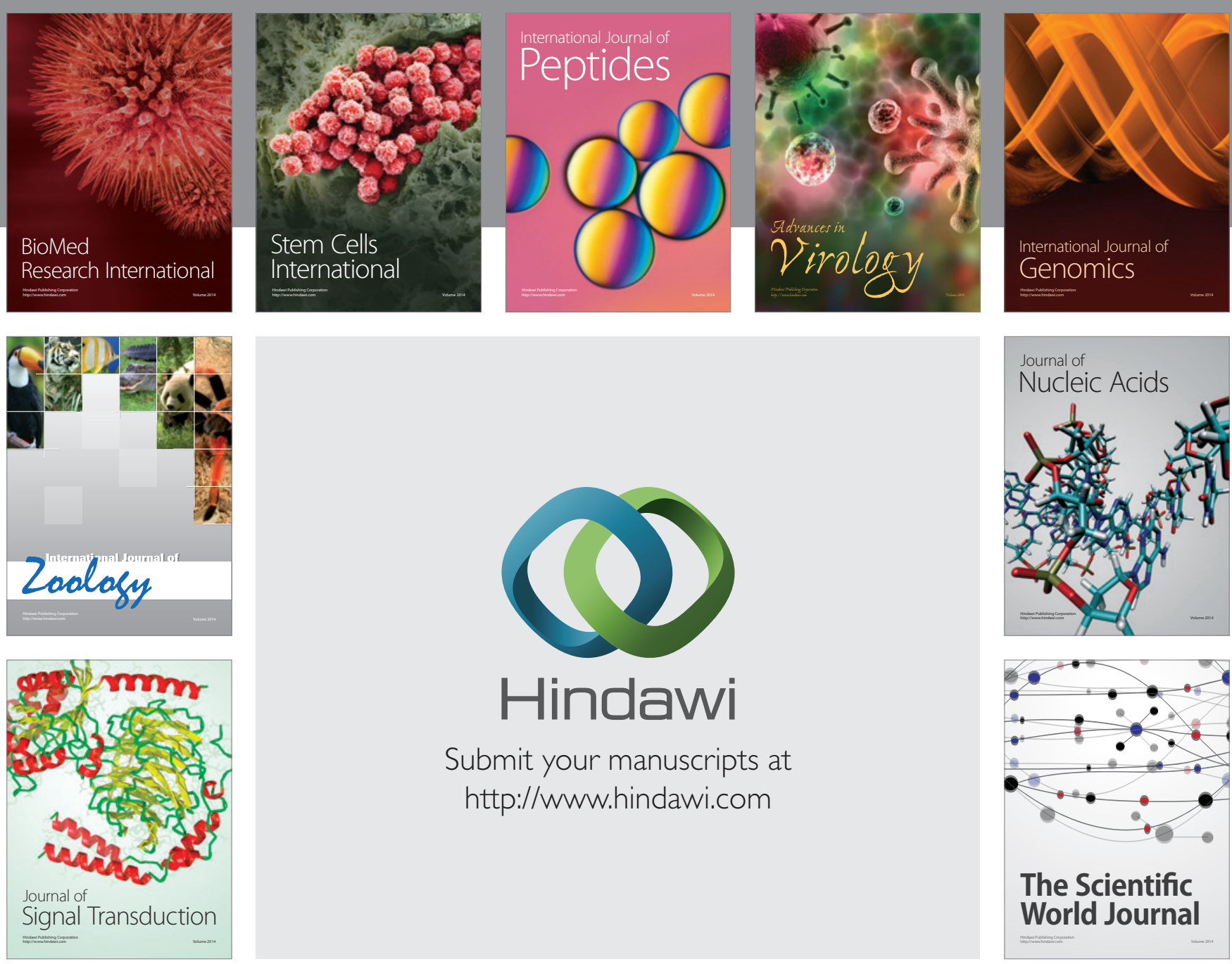

Submit your manuscripts at

http://www.hindawi.com
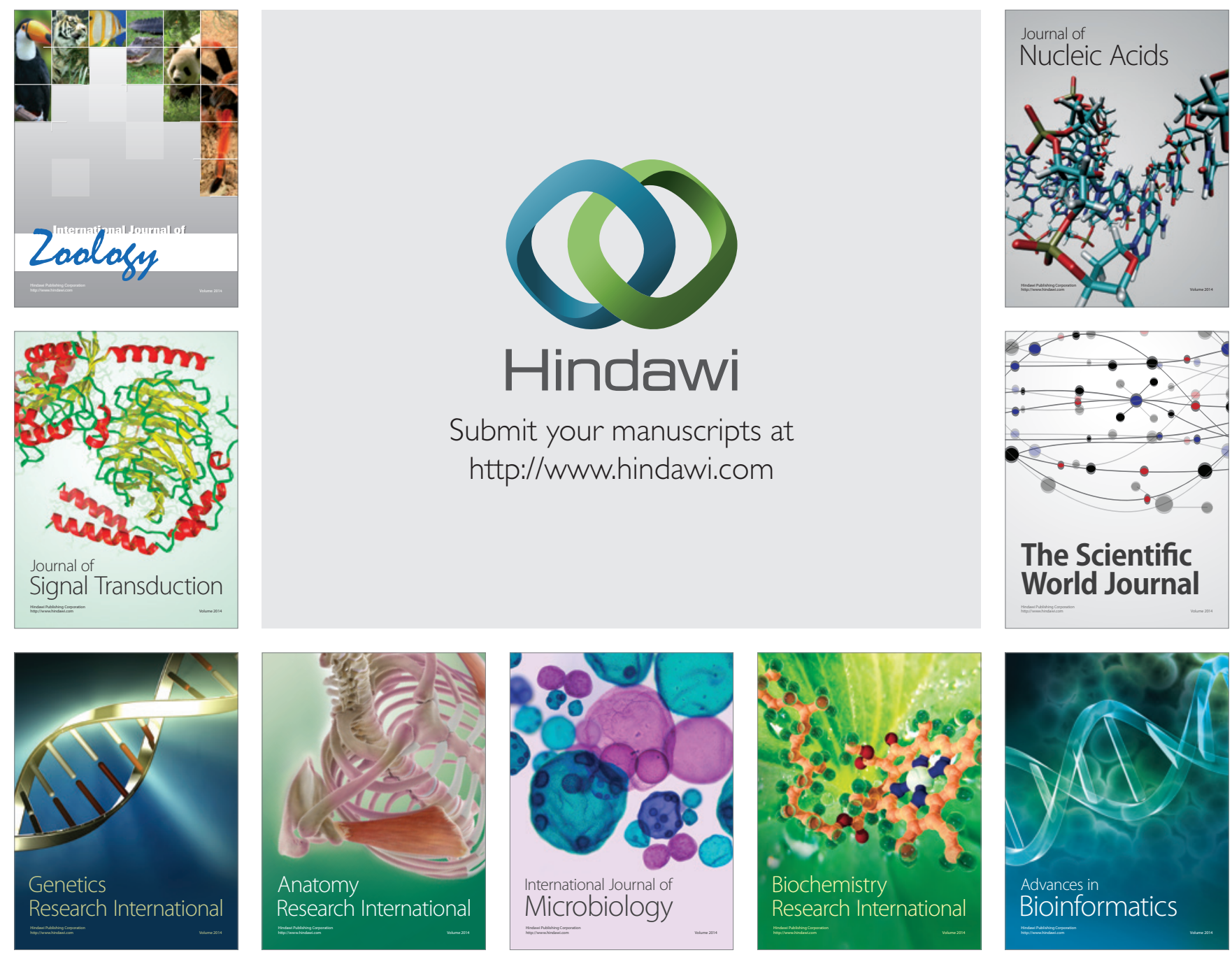

The Scientific World Journal
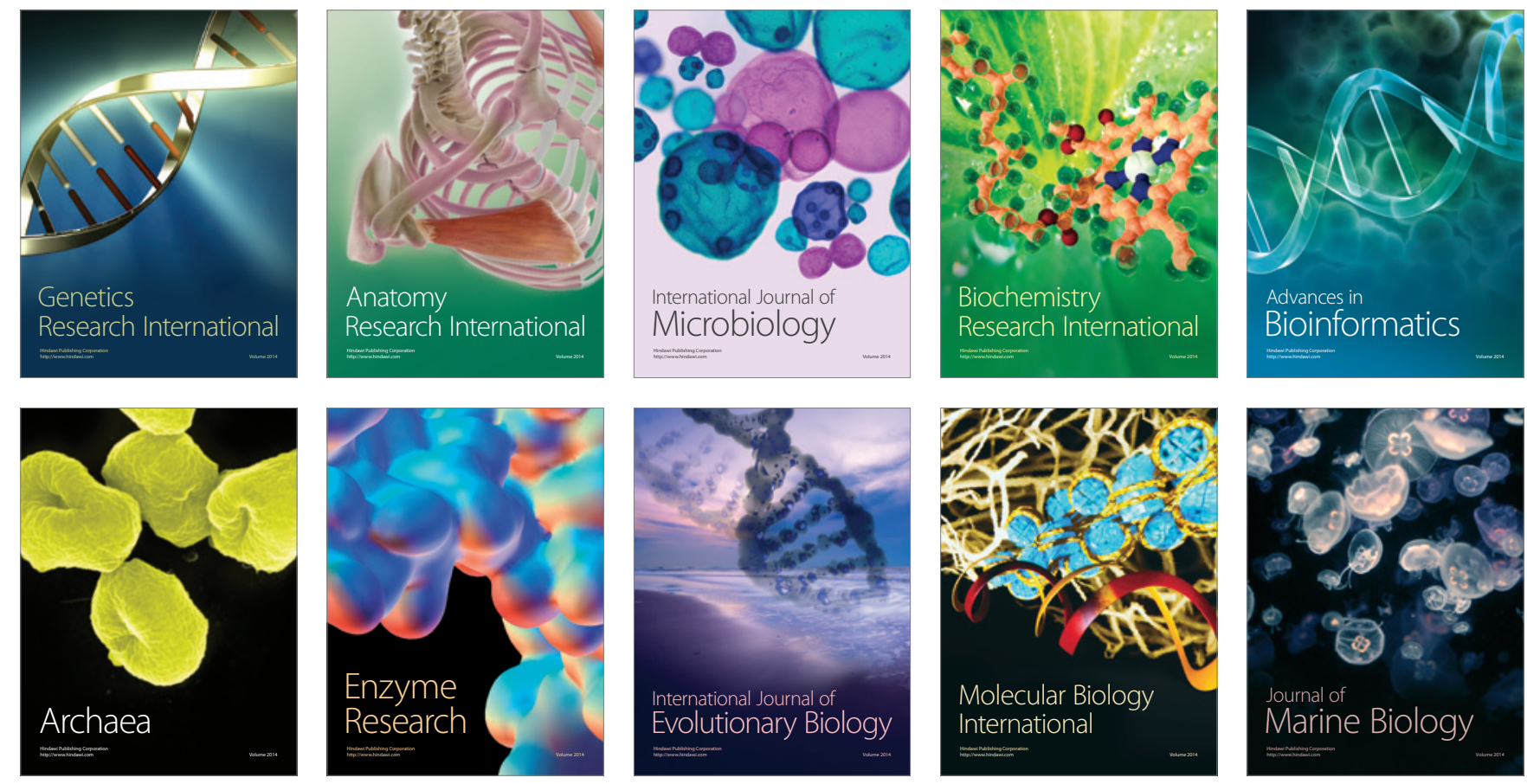